\title{
REVIEWS
}

\section{Asylum Seekers in a Time of Record Forced Global Displacement: the Role of Physicians}

\author{
Katherine C. McKenzie, MD, FACP ${ }^{7}$, Jon Bauer, JD², and P. Preston Reynolds, MD, PhD, MACP

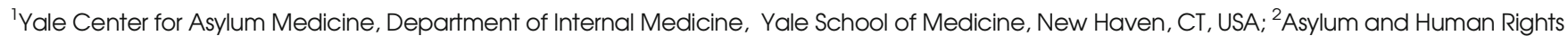 \\ Clinic, University of Connecticut School of Law, Hartford, CT, USA; ${ }^{3}$ Division of General Medicine, Hospitalist Medicine, Geriatrics and Palliative Care, \\ University of Virginia School of Medicine, Charlottesville, VA, USA.
}

In 2016, over 65 million individuals were displaced from their homes due to human rights abuses, and 262,000 people applied for asylum in the USA. Individuals who have experienced persecution are present in many primary and specialty clinics. A medical forensic evaluation can increase the likelihood of a successful asylum case. This paper reviews the legal framework for asylum and the contribution forensic evaluations can make to this vulnerable population. Physicians without asylum expertise can help these patients by recognizing their legal right to residential protection and referring them to lawyers and physicians with expert skills. Performing forensic examinations of asylum seekers offers physicians the opportunity to collaborate with attorneys, immigration officials, and human rights experts. Clinicians who do this work find it personally and professionally rewarding, especially when they impart their expert knowledge and skills to future clinicians by involving trainees in these evaluations. Physicians who encounter refugees or asylum seekers in their roles as providers or as preceptors should have familiarity with the field of asylum medicine to enhance the comprehensive care they deliver.

KEY WORDS: immigrant health; vulnerable populations; global health; legal issues; human rights.

$\mathrm{J}$ Gen Intern Med 34(1):137-43

DOI: $10.1007 / \mathrm{s} 11606-018-4524-5$

(c) Society of General Internal Medicine 2018

\section{BACKGROUND}

In 2016, over 65 million individuals were forcibly displaced from their homes as a result of conflict or human rights violations. ${ }^{1}$ Countless people live in danger of injury or death because of their fundamental identities or beliefs. Men and women are detained, tortured, and killed when they oppose repressive governments. Ethnic or religious groups face attack. Sexual orientation can lead to criminal prosecution and extrajudicial persecution. ${ }^{2}$ Women have no protection from intimate partner violence in societies that consider it a "private issue,"3 and face other gender-specific harms such as forced marriage, honor killings, and female genital cutting. ${ }^{4}$ In some

Received May 30, 2017

Revised January 23, 2018

Accepted May 11, 2018

Published online June 15, 2018 countries, individuals face threats from gangs that act as de facto governments, and are targeted for death if they resist the gang's authority. ${ }^{5}$

Many of these individuals leave their homes under duress to seek safety elsewhere. Those who manage to make it to the USA can apply for asylum in this country. The USA received 262,000 asylum applications in 2016, an increase of $52 \%$ from the year before and over twice as many as in $2014 .^{1}$

Physicians are uniquely positioned to help this vulnerable group of individuals. A medical examination can contribute to a successful asylum claim by documenting the effects of persecution or torture. ${ }^{6}$ One study found that asylum seekers with a medical evaluation performed by a health professional were granted asylum $89 \%$ of the time, compared with a national average rate of $37.5 \%{ }^{7}$

This paper reviews the contributions a physician can make in performing medical forensic examinations of asylum seekers. A psychological evaluation may be included, but is often conducted separately by a mental health specialist. ${ }^{8}$

Asylum medicine offers an opportunity for interdisciplinary cooperation between physicians, human rights experts, and immigration law professionals. ${ }^{9}$ It also allows physicians to participate in global human rights at a local level (see Table 1 for a listing of some of the leading groups involved in asylumrelated advocacy and human rights work). Familiarity with the effects of torture and persecution and an understanding of the asylum process are also important for physicians generally. One study demonstrated that one in nine foreign-born patients seen in an urban clinic had been a victim of torture. ${ }^{10}$ Health professionals encountering such patients in their practice can refer them for legal help, provide medical documentation that may assist their asylum claims, and make referrals for specialized care.

\section{HISTORICAL AND LEGAL PRECEDENTS}

For thousands of years, a tradition has existed whereby societies have offered refuge to those facing persecution. ${ }^{11}$ The modern history of asylum dates to the aftermath of World War II. Responding to the large number of refugees, the United Nations (UN) established policies providing a framework for protecting refugees fleeing persecution. 
Table 1 Human Rights Infrastructure Relating to Asylum

\begin{tabular}{|c|c|c|}
\hline Organization & Role & Website(s) \\
\hline Physicians for Human Rights and & Provide asylum seekers and their attorneys referrals & http://physiciansforhumanrights.org/ \\
\hline HealthRight International & $\begin{array}{l}\text { to physicians and hold trainings for health professionals } \\
\text { interested in performing forensic evaluations }\end{array}$ & https://healthright.org/ \\
\hline Torture survivor clinics & $\begin{array}{l}\text { Provide medical care for torture survivors, perform } \\
\text { evaluations }\end{array}$ & $\begin{array}{l}\text { http://www.survivorsoftorture.org/ } \\
\text { http://www.cvt.org/ }\end{array}$ \\
\hline $\begin{array}{l}\text { Private immigration attorneys, non-profit } \\
\text { immigration law firms, and law school } \\
\text { legal clinics }\end{array}$ & Provide legal representation to asylum seekers & $\begin{array}{l}\text { http://www.aila.org } \\
\text { http://www.immigrationadvocates. } \\
\text { org/nonprofit/legaldirectory }\end{array}$ \\
\hline UN High Commissioner for Refugees & $\begin{array}{l}\text { Works on behalf of refugees worldwide, compiles } \\
\text { reports and statistics relating to refugees and asylum } \\
\text { seekers }\end{array}$ & $\begin{array}{l}\text { http://www.refworld.org/ } \\
\text { http://www.unhcr.org/en-us }\end{array}$ \\
\hline US Department of State & $\begin{array}{l}\text { Prepares annual country reports on human rights } \\
\text { practices that are frequently used as evidence in asylum } \\
\text { cases }\end{array}$ & https://www.state.gov/j/drl/rls/hrrpt/ \\
\hline US Department of Homeland Security, and & Administer the US asylum system, compile information & https://www.uscis.gov/humanitarian/ \\
\hline $\begin{array}{l}\text { US Department of Justice Executive Office } \\
\text { for Immigration Review }\end{array}$ & and statistics on asylum cases & $\begin{array}{l}\text { refugees-asylum/asylum } \\
\text { https://www.justice.gov/eoir }\end{array}$ \\
\hline Immigration Equality & Advocacy and information on LGBT asylum & http://www.immigrationequality.org/ \\
\hline Center for Gender and Refugee Studies & $\begin{array}{l}\text { Information and advocacy relating to gender-based } \\
\text { persecution }\end{array}$ & https://cgrs.uchastings.edu/ \\
\hline Amnesty International, Human Rights & Engage in human rights advocacy and prepare reports & http://www.amnestyusa.org/ \\
\hline Watch, and Human Rights First & on human rights abuses faced by asylum seekers & $\begin{array}{l}\text { https://www.hrw.org/ } \\
\text { http://www.humanrightsfirst.org/ }\end{array}$ \\
\hline
\end{tabular}

The 1948 Universal Declaration of Human Rights declared that "[e]veryone has the right to seek and to enjoy in other countries asylum from persecution." 12 The 1951 UN Convention Relating to the Status of Refugees and its 1967 Protocol define a refugee as "any person who . . . owing to a wellfounded fear of being persecuted for reasons of race, religion, nationality, membership of a particular social group or political opinion, is outside the country of his nationality and is unable or... unwilling to avail himself of the protection of that country." 13 This treaty obliges states not to expel or return a refugee to a country where his or her life or freedom would be threatened. ${ }^{14}$ The US ratified the UN Protocol in 1968, and in 1980, the US enacted the Refugee Act, which made this international obligation part of US law and created a procedure for granting asylum to noncitizens facing persecution in their home countries. $^{15}$

\section{THE PROCESS FOR ADMITTING REFUGEES AND ASYLUM SEEKERS}

The Refugee Act set up two distinct processes for allowing people who meet the refugee definition to come to the USA: resettlement and asylum. Those admitted through the refugee resettlement program typically go through 18-24 months of vetting while living in refugee camps or urban settings abroad. Refugee admissions are limited to a maximum number set each year by the President in consultation with Congress and were recently cut by nearly $50 \%$ to 45,000 , the lowest level in decades. ${ }^{16}$

In contrast, any person who is in the USA or arrives at the US border has the right to apply for asylum. An asylum seeker may initially enter with legal documents such as a tourist or student visa or may arrive with no legal status. Some asylum seekers are detained while trying to enter without authorization or after being caught inside the USA by immigration authorities, and may have to pursue their asylum claims while in detention. ${ }^{17}$ An application for asylum generally must be filed within a year after arrival, although there are exceptions to this rule (including for minors and delays due to mental or physical disability). ${ }^{18}$ To be granted asylum, an individual must show that he or she meets the refugee definition and that none of the various bars to asylum apply (e.g., serious criminal conduct, persecution of others, or terrorist ties). The burden of proof is on the asylum applicant, and applicants are expected to present corroboration of their claims where available. Persons seeking asylum, unlike criminal defendants, have no right to counsel at government expense. ${ }^{19}$

In recent years, approximately 25,000 persons have been granted asylum annually. ${ }^{20}$ Those granted asylum (known as "asylees"), like refugees admitted through the resettlement program, gain work authorization, the right to remain in this country lawfully, the ability to bring in a spouse and/or minor children from abroad, and ultimately, the right to apply for permanent resident status and citizenship. ${ }^{21}$

\section{THE STANDARD FOR BEING GRANTED ASYLUM}

To meet the "refugee" definition and qualify for asylum, applicants must show that they suffered past persecution and/or have reasonable grounds to fear future persecution, and that the persecution was or will be inflicted based on one of five protected grounds: political opinion, race, religion, nationality, or membership in a particular social group. Claims covered under the "particular social group" category may include persecution based on sexual orientation or gender identity, ${ }^{22}$ gender-based harms such as domestic violence or 
female genital mutilation, ${ }^{23}$ and, in some circumstances, targeted gang violence. ${ }^{24}$

Persecution requires more than mere discrimination or harassment. Harms that have been found to constitute persecution include torture, rape, repeated physical abuse, prolonged imprisonment, severe mental or emotional abuse, imminent and menacing death threats, and extreme economic punishments. $^{25}$

\section{PERSECUTION AND TORTURE}

Physicians, especially those serving immigrant populations, may encounter patients who have been tortured. ${ }^{26}$ The UN Convention Against Torture (CAT) defines torture as "any act by which severe pain or suffering, whether physical or mental, is intentionally inflicted on a person" for purposes of punishment, coercion, obtaining information, or discrimination. ${ }^{27}$ Some types of torture along with the resultant injuries are outlined in Table $2 .^{28-31}$ Torture may not leave a permanent physical scar, but instead can manifest as post-traumatic stress disorder (PTSD), severe anxiety or depression, or other mental illnesses. $^{32}$

Torture motivated by any of the five protected grounds is persecution that makes an individual eligible for asylum. But torture, regardless of why it is inflicted, can qualify a person for immigration relief. Under US regulations implementing the CAT, a person cannot be deported to any country where they would face torture from the authorities or inflicted by private parties with official acquiescence. ${ }^{33}$

\section{THE ROLE OF THE MEDICAL FORENSIC EVALUATION FOR ASYLUM SEEKERS}

A forensic medical evaluation usually is initiated by a referral from an immigration attorney or advocacy organization. An evaluation can play a crucial role in persuading the adjudicator that the applicant's account of persecution is credible by establishing that the person has scars, injuries, or physical or mental symptoms that are consistent with the applicant's description of the mistreatment they suffered. ${ }^{7}$

Many physicians have or can readily obtain skills that enable them to assess scars and other abnormalities in asylum seekers. Trainings are conducted by human rights organizations such as Physicians for Human Rights or HealthRight International, or at academic asylum programs. Most trainings are a half or full day. There is no certification granted for training, but judges and immigration officials are likely to give more weight to a physician's conclusions if he or she has been trained to conduct evaluations and prepare reports for asylum cases. Most physicians perform the evaluations on a pro bono basis, although some charge a small fee to cover their administrative expenses.

Evaluations can occur in a medical asylum clinic, physician's private office, or an attorney's office. As the evaluation is not considered medical care, malpractice insurance and creating an electronic health record are not necessary, although standards may vary by institution.

For asylum seekers with ongoing medical or mental health issues, the physician should speak with the attorney about community resources, including medical and psychiatric care, for which the client may be eligible. Many asylum programs

Table 2 Common Torture Methods

\begin{tabular}{|c|c|c|c|c|}
\hline Form of torture & Common weapon or injury & Acute injury & Chronic scar & Functional sequelae \\
\hline Blunt trauma & Baton, fists, whips, kicking & Contusion, fracture & $\begin{array}{l}\text { Hyper- or hypo-pigmented, } \\
\text { irregular borders, } \\
\text { hypertrophic }\end{array}$ & Uncommon \\
\hline Sharp trauma & Knife, bayonet & Laceration & $\begin{array}{l}\text { Well demarcated, often } \\
\text { linear, hypertrophic }\end{array}$ & Uncommon \\
\hline Thermal trauma & $\begin{array}{l}\text { Cigarette, hot iron, caustic } \\
\text { substance }\end{array}$ & Burn & $\begin{array}{l}\text { Shape is instrument } \\
\text { dependent; nonspecific if } \\
\text { liquid }\end{array}$ & Uncommon \\
\hline Electrical shocks & Electrodes & $\begin{array}{l}\text { Burns; shape is } \\
\text { instrument dependent }\end{array}$ & Typically well demarcated & Uncommon \\
\hline Forced position & Suspension, confined space & Uncommon & Uncommon & $\begin{array}{l}\text { Chronic pain, motor } \\
\text { and sensory deficits }\end{array}$ \\
\hline Asphyxiation & Water, cloth, chemicals & Uncommon & Uncommon & $\begin{array}{l}\text { Cognitive and memory } \\
\text { impairment }\end{array}$ \\
\hline $\begin{array}{l}\text { Falanga/falanka } \\
\text { (blunt trauma } \\
\text { to the bottom of } \\
\text { the feet) }\end{array}$ & Sticks, rods & $\begin{array}{l}\text { None or foot } \\
\text { swelling/bruising }\end{array}$ & None or fallen arch & $\begin{array}{l}\text { Ambulatory impairment, } \\
\text { chronic pain }\end{array}$ \\
\hline $\begin{array}{l}\text { "Telefono" (blunt } \\
\text { trauma to ears) }\end{array}$ & Hands, fists & Swelling of pinna, none & Pinna scars, none & $\begin{array}{l}\text { Chronic pain, hearing } \\
\text { loss }\end{array}$ \\
\hline Rape, sexual torture & Penis, other foreign objects & $\begin{array}{l}\text { Lacerations, swelling, } \\
\text { bleeding }\end{array}$ & Usually none & $\begin{array}{l}\text { Sexual dysfunction, } \\
\text { psychological scars }\end{array}$ \\
\hline $\begin{array}{l}\text { Inhumane } \\
\text { conditions } \\
\text { of confinement }\end{array}$ & $\begin{array}{l}\text { Crowding, sensory } \\
\text { deprivation, isolation, } \\
\text { inadequate food and } \\
\text { water, temperature extremes, } \\
\text { unhygienic conditions, } \\
\text { restricted use of bathrooms }\end{array}$ & $\begin{array}{l}\text { Infections, } \\
\text { malnutrition, } \\
\text { acute medical illnesses }\end{array}$ & & $\begin{array}{l}\text { Post-traumatic stress } \\
\text { disorder }\end{array}$ \\
\hline
\end{tabular}


have relationships with clinics for the underserved, and some programs provide comprehensive follow-up care for torture victims.

\section{THE ISTANBUL PROTOCOL}

The Istanbul Protocol Manual on the Effective Investigation and Documentation of Torture and Other Cruel, Inhuman or Degrading Treatment or Punishment is the guiding document for forensic evaluations of survivors of torture, persecution, and ill treatment. ${ }^{34}$ Developed for the UN by a group of physicians, attorneys, and human rights experts, the Istanbul Protocol is the international standard for assessing, documenting, and reporting allegations of torture. The guidelines recommend the following: (1) describing the events of persecution which led to the asylum seeker's physical findings; (2) documenting symptoms that could be related to ill treatment; (3) commenting on the degree of consistency between the applicant's history of alleged trauma and physical findings; (4) explaining possible medical causes of discrepant history; and (5) providing testimony in writing, and sometimes also in court.

\section{PERFORMING EVALUATIONS}

When an asylum seeker claims to be a victim of persecution or torture and reports physical scars and/or mental health sequelae, the physician must assess the consistency between the history reported by the individual and the medical findings. Physicians performing these medical forensic examinations generally do not provide medical care because the purpose of the evaluation is to gather evidence for use in legal proceedings. Physicians must maintain objectivity and avoid any suggestion of advocacy. Because this is a forensic evaluation, and not ongoing care, some physicians do not use the term "patients" to refer to these individuals.

The client's attorney documents the applicant's personal history and the events that gave rise to any injuries and provides this information to the physician in advance of the evaluation, often in the form of a detailed client affidavit or declaration. The referring attorney may also provide pertinent background information on the client's home country, or the physician may research this by consulting human rights reports prepared by the US State Department or NGOs such as Human Rights Watch or Amnesty International. The physician confers with the legal team to arrange an appointment as well as an interpreter, as needed. It is desirable to find someone fluent in the client's language who is not a friend or family member.

If trainees may be present to observe or participate in the evaluation, the attorney should obtain permission from the client for persons other than the physician conducting the evaluation to be involved. ${ }^{35}$ Sometimes clients express a preference regarding the gender of the evaluator; for example, when the client has been a victim of gender violence. ${ }^{36}$
Minimal equipment is necessary for the medical evaluation. A private room equipped with an exam table, and seating for client, translator, evaluator, and trainees should be assured. Necessary equipment may include a tape measure, stethoscope, otoscope, light source, and speculum depending on injuries.

Physicians should document all findings of scars on blank body diagrams and take photographs if the applicant allows. ${ }^{37}$ If the person endured mistreatment that could have mental health sequelae, it is critical to obtain a history of any symptoms that may be consistent with post-traumatic stress disorder, anxiety, depression, phobias, and neurologic manifestations of trauma such as severe headaches or memory and cognitive deficits.

Re-traumatization can occur as the client recalls their persecution. ${ }^{30}$ To minimize this, the exam should be conducted in an empathetic and respectful manner, while maintaining strict objectivity. Asylum seekers should be encouraged to speak with their current care providers or referred for mental health care if they experience distress during the evaluation or suffer worsening symptoms thereafter.

Since the medical forensic examination may be used as supporting documentation to an application for asylum, the physician must obtain an account of the ill treatment that is as precise and explicit as possible. For example, if an asylum seeker is recounting an incident of violence, it will be important to learn details such as the number of perpetrators involved in the assault, the type of weapon(s) or torture methods used, where on the body blows or other torture methods were inflicted, and the time elapsed during key events. These details will be important in assessing the consistency of any physical scars or symptoms with the individual's story. A medical history should also be taken to identify any medical conditions or injuries besides the persecution, such as abrasions from an accident that may account for any scars or symptoms.

Despite the importance of specificity in recounting torture and ill treatment, clients are not always able to provide detailed or completely consistent accounts of events. ${ }^{38}$ Head trauma can interfere with recall. Detention may result in sensory deprivation, which can impair temporal and spatial memory. Post-traumatic stress disorder, depression, and anxiety can affect memory. ${ }^{39}$ In such cases, the physician should outline the potential medical causes of impaired or inconsistent memory.

\section{WRITING AFFIDAVITS AND TESTIFYING IN COURT}

After performing a forensic evaluation, the physician will draft a report; this process may take several hours. The physician begins the report by describing his or her expertise, continues with the history elicited from the client, and then documents the physical findings and mental health sequelae. The report must include a discussion of the consistency of the findings with the alleged history of torture or persecution, as described in the Istanbul Protocol (Table 3). Because this report will be 
Table 3 Degrees of Consistency (from the Istanbul Protocol)

\begin{tabular}{ll}
\hline \hline $\begin{array}{l}\text { Not consistent } \\
\text { with }\end{array}$ & $\begin{array}{l}\text { The lesion could not have been caused by the } \\
\text { trauma described. }\end{array}$ \\
Consistent with & $\begin{array}{l}\text { The lesion could have been caused by the trauma } \\
\text { described, but it is nonspecific and there are } \\
\text { many other possible causes. }\end{array}$ \\
Highly & $\begin{array}{l}\text { The lesion could have been caused by the trauma } \\
\text { described, and there are few other possible } \\
\text { causes. }\end{array}$ \\
Typical of & $\begin{array}{l}\text { This is an appearance that is usually found with } \\
\text { this type of trauma, but there are other possible } \\
\text { causes. } \\
\text { This appearance could not have been caused in } \\
\text { any way other than that described. }\end{array}$ \\
Diagnostic of &
\end{tabular}

used as evidence in a legal proceeding, it usually takes the form of an affidavit or declaration under penalty of perjury signed by the physician.

If the physician, in preparing the report, discovers that the information obtained from the client during the medical interview differs from information the client gave to the attorney, the physician should discuss this with the attorney, but the physician must always function as an independent expert and rely foremost on the information acquired directly from the client. The weight placed on a physician's opinion depends on their perceived independence, as well as on their credentials and the quality and thoroughness of the evaluation and report. ${ }^{40}$

Most asylum medical evaluations require only a written report from a physician. Occasionally, a physician will be asked to testify in person or by telephone at a hearing. The asylum seeker's attorney can help the physician prepare through a pre-hearing conversation or practice session. The physician may be asked questions by the client's attorney, the government attorney, and/or the immigration judge. In testifying, the physician should bear in mind that she is only responsible for providing a medical opinion and is not there to offer opinions on the asylum seeker's credibility, human rights conditions in the client's home country, or whether an asylum grant is appropriate. The government attorney may question whether the scars or symptoms are a result of the torture or other mistreatment alleged by the asylum applicant or could have been produced by other causes. The physician should reiterate the information in the medical-legal affidavit regarding the degree of consistency between the scars and the individual's account of persecution but must concede that the physician cannot say with certainty that the asylum seeker's account is true.

\section{EDUCATING AND TRAINING MEDICAL STUDENTS, RESIDENTS, AND FELLOWS}

As the number of asylum seekers increases, it becomes imperative to educate medical students, residents, and fellows about health and human rights, and the unique contribution a physician can make to asylum medicine. Trainees can learn skills in asylum evaluation and care of torture survivors through formal curriculum instruction as well as direct involvement in performing evaluations. ${ }^{41,42}$

\section{CARING FOR VICTIMS OF TORTURE}

This paper's focus is on how physicians can support individuals seeking asylum by performing much-needed forensic evaluations. Asylum seekers as a group are vulnerable and underserved, by virtue of the trauma they have experienced and their precarious legal circumstances as they await resolution of their case. Although serving as an expert evaluator may preclude providing ongoing care for the same patient, physicians performing asylum evaluations should, at a minimum, make appropriate referrals to health providers who can provide ongoing care, such as community health centers and programs dedicated to serving torture survivors. Keller et al., among others, have written about the medical needs of patients who have been victims of torture. ${ }^{26}$ In addition, physicians can engage in political and human rights advocacy to improve the plight of refugees and asylum seekers in the USA and worldwide.

\section{CONCLUSION}

As long as there is conflict, human rights abuses, and forced displacement, there will be vulnerable individuals who seek asylum in countries other than their own. Physicians are respected witnesses in immigration proceedings and their expert opinion can increase the likelihood that a person will be able to prove their claim for asylum. ${ }^{7}$ Physicians-at all levels of clinical experience-can enhance their evaluative skills by obtaining training and participating in forensic medical evaluations, and in doing so, contribute to global health and human rights. Clinicians who work with asylum seekers in this capacity report finding the work satisfying and rewarding. ${ }^{43,44}$

Corresponding Author: Katherine C. McKenzie, MD, FACP; Yale Center for Asylum Medicine, Department of Internal Medicine Yale School of Medicine, New Haven, CT, USA (e-mail: katherine. mckenzie@yale.edu).

\section{Compliance with Ethical Standards:}

Conflict of Interest: The authors declare that they do not have a conflict of interest.

\section{REFERENCES}

1. UNHCR. Global trends: forced displacement in 2016. 2017.

2. Beyrer C. Pushback: the current wave of anti-homosexuality laws and impacts on health. PLoS Med 2014;11(6):e1001658. https://doi.org/10. 1371/journal.pmed. 1001658

3. Devries KM, Mak JYT, Garcia-Moreno C, Petzold M, Child JC, Falder G, et al. The global prevalence of intimate partner violence against women. Science 2013;340(6140):1527-8. https://doi.org/10.1126/science. 1240937 
4. Musalo K. Personal violence, public matter: evolving standards in gender-based asylum law. Harv Int Rev 2014;36(2):45.

5. Anker D, Lawrence P. "Third generation" gangs, warfare in Central America, and refugee law's political opinion ground. Immigration Briefings. 2014;14-10:1.

6. Scruggs E, Guetterman TC, Meyer AC, VanArtsdalen J, Heisler M. An absolutely necessary piece: a qualitative study of legal perspectives on medical affidavits in the asylum process. J Forensic Legal Med 44:72-8. https://doi.org/10.1016/j.jflm.2016.09.002

7. Lustig SL, Kureshi S, Delucchi KL, Iacopino V, Morse SC. Asylum grant rates following medical evaluations of maltreatment among political asylum applicants in the United States. J Immigr Minor Health 2008;10(1):7-15. https://doi.org/10.1007/s10903-007-9056-8

8. Prabhu M, Baranoski M. Forensic mental health professionals in the immigration process. Psychiatr Clin N Am 2012;35(4):929-46.

9. McKenzie K. Medical evaluation of asylum seekers. In: Annamalai A, editor. Refugee Health Care. New York: Springer; 2014. p. 235-41.

10. Crosby SS, Norredam M, Paasche-Orlow MK, Piwowarczyk L, Heeren T, Grodin MA. Prevalence of torture survivors among foreign-born patients presenting to an urban ambulatory care practice. J Gen Intern Med 2006;21(7):764-8. https://doi.org/10.1111/j.1525-1497.2006. 00488.x

11. Gil-Bazo M-T. Asylum as a general principle of international law. International Journal of Refugee Law 2015;27(1):3-28.

12. Universal declaration of human rights. Art. 14. United Nations; 1948.

13. Convention and protocol relating to the status of refugees. Geneva: Office of the High Commissioner for Refugees; 2010.

14. Convention relating to the status of refugees. Art 33(1).

15. Public Law 96-212. 1980.

16. Proposed refugee admissions for fiscal year 2017: report to the Congress. US Departments of State, Homeland Security and Health and Human Services; 2016.

17. Immigration and Nationality Act, U.S. Code Title 8 § 1158(a)(1), 1225.

18. Code of Federal Regulations, Title 8 § 208.4. 2016.

19. Immigration and Nationality Act US Code Title $8 \S \S 1158,1229 a .2016$.

20. Mossaad D. Annual flow report refugees and asylees 2015. US Department of Homeland Security Office of Immigration Statistics; 2016.

21. Immigration and Nationality Act, US Code Title 8 § 1158-1159. 2016.

22. US Citizenship and Immigration Services. Guidance for Adjudicating Lesbian, Gay, Bisexual, Transgender and Intersex (LGBTI) Refugee and Asylum Claims. 2011.

23. US Department of Justice, Board of Immigration Appeals: Matter of A-RC-G-; 26 I\&N Dec. 388 (BIA 2014). Matter of Kasinga, 21 I\&N Dec. 357 (BIA 1996).

24. U.S. Court of Appeals: Pirir-Boc v. Holder, 750 F.3d 1077 (9th Cir. 2014); Crespin-Valladares v. Holder, 632 F.3d 117 (4th Cir. 2011). LexisNexis Legal Newsroom Immigration Law: Gang Asylum (Guatemala, Mara-18) Victory in Hartford Immigration Court, at https://www.lexisnexis.com/ legalnewsroom/immigration/b/insidenews/archive/2015/03/25/gangasylum-guatemala-mara-18-victory-in-hartford-immigration-court.aspx? Redirected=true. 2015. Accessed March 5, 2018

25. Rempell S. Defining Persecution. Utah Law Review. 2013;283.

26. Keller AS. Caring and advocating for victims of torture. Lancet 2002;360 Suppl:s55-6.

27. Assembly UNG. Convention Against Torture and Other Cruel, Inhuman and Degrading Punishment. 1984

28. Forrest D. Examination for the late physical after effects of torture. Journal of Clinical Forensic Medicine 1999;6(1):4-13.

29. Peel M, Iacopino V, eds. The Medical Documentation of Torture. New York: Cambridge University Press; 2002.

30. Moreno A, Grodin MA. Torture and its neurological sequelae. Spinal Cord 2002;40(5):213-23.

31. Danielsen L, Rasmussen OV. Dermatological findings after alleged torture. Torture 2006;16(2):108-27.

32. Peel M, Iacopino V. The medical documentation of torture. London; San Francisco: Greenwich Medical Media; 2002.

33. Code of Federal Regulations Title 8 §§ 1208.16-1208.18. 2016.

34. United Nations, Office of the High Commissioner for Human Rights Istanbul Protocol: Manual on the effective investigation and documentation of torture and other cruel, inhuman or degrading treatment or punishment. United Nations, New York. 2004.

35. Physicians for Human Rights. Examining asylum seekers: a clinician's guide to physical and psychological evaluations of torture and illtreatment. Cambridge, MA: Physicians for Human Rights; 2012.

36. Kallivayalil D. Women seeking political asylum: negotiating authority, gender and a lost home. Women \& Therapy 2013;36(3-4):319-31.
37. Park R, Oomen J. Context, evidence and attitude: the case for photography in medical examinations of asylum seekers in the Netherlands. Soc Sci Med 2010;71(2):228-35.

38. Herlihy J, Scragg $\mathbf{P}$, Turner S. Discrepancies in autobiographical memories-implications for the assessment of asylum seekers: repeated interviews study. BMJ 2002;324(7333):324-7.

39. Graessner S, Ahmad S, Merkord F. At the Side of Torture Survivors. Baltimore: The Johns Hopkins Press; 2001.

40. Lawrance BN, Ruffer G. Adjudicating refugee and asylum status: the role of witness, expertise, and testimony. 2015.

41. Yale Center for Asylum Medicine. http://medicine.yale.edu/intmed/ genmed/asylum/. Accessed 5 March 2018

42. Asgary RG, Metalios EE, Smith CL, Paccione GA. Evaluating asylum seekers/torture survivors in urban primary care: a collaborative approach at the Bronx Human Rights Clinic. Health Hum Rights 2006;9(2):164-79.

43. Roth $\mathbf{K}$. Giving refuge: reflections on working with asylum seekers. J Pain Symptom Manag 2010;40(1):149-54.

44. Mishori R, Hannaford A, Mujawar I, Ferdowsian H, Kureshi S. "Their stories have changed my life": clinicians' reflections on their experience with and their motivation to conduct asylum evaluations. J Immigr Minor Health 2016;18(1):210-8. https://doi.org/10.1007/s10903-014-0144-2

\section{APPENDIX}

Mr. Garcia is a 42-year-old man. He is Spanish speaking only. Since his initial visit to your clinic, Mr. Garcia has been treated for leg pain with a reported history of trauma secondary to a motor vehicle accident he sustained when he crossed into the USA. A colleague in the legal clinic at your university asks if you will conduct a medical forensic evaluation since you have expertise in this field, and your colleague believes his client sustained torture because of his political affiliation with a democratic party in his home country.

You receive the individual's affidavit and review it. When the interpreter and individual arrive, you escort them into a room equipped to conduct a history and physical examination. You explain the evaluation you have been asked to conduct is not part of his routine medical care, but is focused on evaluating his claims of torture.

Over the next several hours, you gather and clarify through the interpreter, in as much detail as possible, the violence and neardeath experience he sustained, his prolonged recovery and efforts to hide from the perpetrators, and the subsequent death threats which forced him to flee to the USA. You carefully ask questions in several different ways at various points in the history to verify the story he is reporting to you, and to determine if it is consistent with the testimony provided to your colleague in his legal affidavit. You also explore any injuries, traumas, or illnesses he has suffered that are unrelated to the persecution.

After completing the history, you examine him, first focusing on each scar-its length, width - and then assess the likelihood of it being the result of blunt trauma, knife-wound trauma, or a surgical incision. You complete a thorough musculoskeletal examination focusing on deformities, limitations in range of motion, and resulting disabilities. After completing the physical examination, you ask questions about his mental health, whether he experienced or continues to experience symptoms consistent with post-traumatic stress disorder, 
anxiety, depression, or other mental health disorders. You document your physical and mental health findings and illustrate the scars in drawings. He allows you to take photographs which you plan to include in your final report. While this examination has taken several hours, you realize there may be questions that arise as you write up your report, and ask if he would be willing to see you again if necessary.

You provide Mr. Garcia's attorney with a medical report that lists your qualifications, describes the evaluation you conducted, and details your findings. In the report, you describe and include photographs of several scars you found during your examination. You explain that two of Mr. Garcia's scars are highly consistent with his account of how his assailants cut him with a knife, while another is consistent with a blow to his face with truncheon that he described. You also note that he has a scar on his leg that appears to be the result of his car accident and unrelated to his torture. You also note that Mr. Garcia describes nightmares, insomnia, intrusive thoughts, and hypervigilance that are consistent with post-traumatic stress symptoms.

After writing up your report, you realize that his primary care physician, a resident in your faculty-resident teaching clinic, did not know this person's history. You ask Mr. Garcia if he would grant you permission to discuss your findings with his medical doctor. He agrees that this information may enable his doctor to provide more insightful and empathic care. Fortunately, the PTSD symptoms are abating with psychiatric care and with support he receives from his fiancé, a woman he knew growing up in his home country who is a legal resident of the USA, and the hope provided by his lawyer and you in his efforts to be granted asylum. 